\title{
Diş Hekimliği Fakültesi Son Sınıf Öğrencileri ve Diş Hekimlerinin Maksillofasiyal Travma Muayenesi Konusunda Bilgi Düzeylerinin Değerlendirilmesi
}

\author{
Evaluation of Knowledge Levels of Senior Dental \\ Students and Dentists on Maxillofacial Trauma Assessment
}
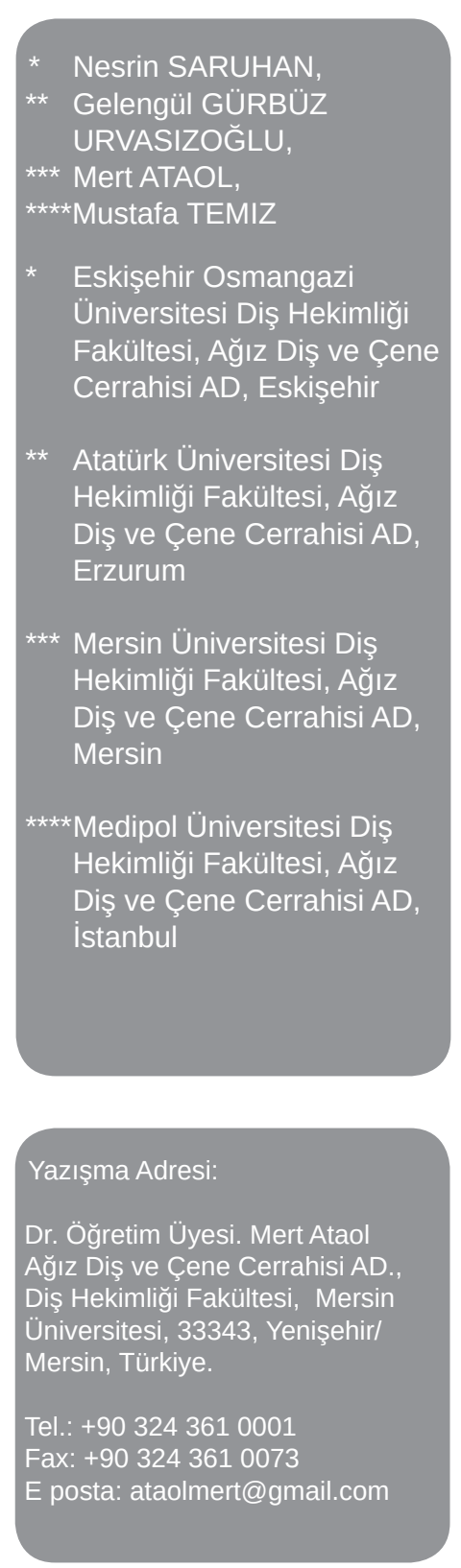

\section{Öz}

Amaç: Bu çalışmanın amacı diş hekimliği fakültesi son sınıf öğrencileri ve mezun diş hekimleri için maksillofasiyal travmalara yaklaşım ile ilgili bilgi düzeylerini değerlendirmektir. Yöntem: Atatürk Üniversitesi Diş Hekimliği Fakültesinde son sınıfta okuyan öğrenciler ve Erzurum ilinde çalışmakta olan diş hekimlerine, maksillofasiyal travma bilgi düzeylerini ve yaklaşımlarını değerlendirmek amacıyla hazırlanan 20 soruluk bir anket formu uygulandı. Çalışmada 91 son sınıf öğrencisi ve 51 mezun diş hekimi yer almıştır. Bulgular: Bilgi düzeyini değerlendiren 13 sorunun 11'inde, doğru cevabın, sadece 2 soruda ise yanlış cevap seçeneğinin daha çok tercih edildiği görülmüştür. Katılımcılara yöneltilen ve klinik yaklaşımı değerlendiren 7 adet subjektif değerlendirme sorularının tamamı için, her iki grup tarafından da negatif sonuçlar elde edilmiştir. Sonuç: Hem son sınıf öğrencisi hem de mezun diş hekimlerinin maksillofasiyal travmalar konusundaki bilgi düzeylerinin kabul edilebilir olmasına rağmen katılımcıların bu konuda yeterli özgüvene sahip olmadıkları görülmüştür. Bu konudaki teorik bilgilerin, klinik olarak güçlendirilmesi gerektiği ve gereken eğitim stratejisinin oluşturulması gerekliliği sonucuna varılmıştır.

Anahtar Kelimeler: Maksillofasiyal Travma, Diş Hekimliği Öğrencisi, Diş Hekimi, Bilgi Düzeyi

\section{Abstract}

Purpose: The aim of this study is to evaluate the level of knowledge about the maxillofacial trauma approach for senior dental school students and dentists. Methods: A 20-question survey was prepared to evaluate the knowledge levels and approaches of maxillofacial trauma and conducted to the last year students of Ataturk University Faculty of Dentistry and dentists working in the province of Erzurum. The study included 91 senior dental students and 51 dentists. Results: For 11 answers of the 13 questions that assessed the level of knowledge, it's showed that the correct answer was preferred, only for two answers, the false choice was preferred. For all of the 7 subjective assessment questions directed to the participants and assessing the clinical approach, negative results were obtained by both groups. Conclusion: Despite the level of knowledge about maxillofacial trauma for both senior students and dentists were acceptable, it's showed that participants were not self-confident enough in this issue. This is concluded that theoretical knowledge on this 
issue should be strengthened clinically and a suitable education strategy should be established

Keywords: Maxillofacial Trauma, Dental Students, Dentists, Level of Knowledge

\section{Giriş}

Maksillofasiyal travmalı hastalarda yapılan ilk değerlendirme yaralanma bölgesinden ziyade yaşamsal fonksiyonların değerlendirilmesini içermektedir. Bu birincil değerlendirme sonucunda solunum ve dolaşımdaki sıkıntıların tespiti ve giderilmesine yönelik işlemler yapılır. Birincil değerlendirme genellikle sağlık merkezlerinin acil servisleri ve acil müdahale ekipleri tarafından gerçekleştirilir (1).

Maksillofasiyal bölgenin, hem çiğneme ve konuşma fonksiyonu hem de estetik gereksinimleri karşıladığı düşünüldüğünde travma hastasına ilk muayenede yaklaşım ve doğru teşhis oldukça büyük öneme sahip olduğu ortaya çıkmaktadır. Diş hekimleri, hastanın yaşamsal fonksiyonları stabil hale geldikten sonra, yaralanma alanının özellikle muayene ve teşhis aşamasına katılabilmektedirler(2). Diş hekimlerinin bu konudaki bilgi ve farkındalık düzeyleri; doğru tanıya gidilmesi, hastaların uygun tedaviye en kısa sürede ulaşabilmeleri açısından önemlilik arz etmektedir.

Klinisyenlerin belirli bir konuda bilgi düzeyinin ölçülmesi ve sonuçlara göre gerekli ise eğitim desteğinin sağlanması ve lisans eğitiminde uygun düzenlemelerin yapılması amacıyla anket veya geri bildirim formları değerli kaynaklardır(3,4). Bu tür kaynaklarla elde edilen veriler doğru şekilde değerlendirildiğinde; klinisyenlerin bilgi düzeylerinin yükseltilmesi, bu durumlarla ilgili hem hekimlerin mesleki sorumluluğu hem de eğitim veren kurumların yaklaşımlarının geliştirilmesi ve ayrıca hastalara sunulan hizmetin iyileştirilmesi sağlanabilir.

Bu çalışmanın amacı stajyer diş hekimleri ve mezun diş hekimleri için maksillofasiyal travmalara yaklaşım ile ilgili bilgi düzeylerini değerlendirmektir.

\section{Yöntem}

Diş hekimliği 5. sınıf öğrencileri ve mezun diş hekimleri için maksillofasiyal travma bilgi düzeylerini ve yaklaşımlarını değerlendirme amacıyla 20 soruluk bir anket formu tasarlandı. Anket oluşturulurken, maksillofasiyal travma vakalarının değerlendirilmesi, acil müdahale ve takip açısından önem taşıyan temel konuların belirlenmesi ve bu konulardaki bilgi seviyesinin değerlendirilmesi amaçlandı. Bu amaçla, kaynak olarak "Tintinalli's Emergency Medicine: A Comprehensive Study Guide, 8th Edition (Tintinalli Acil Tıp: Kapsamlı Bir Çalışma Kılavuzu, 8. Baskı), McGraw-Hill, New York, 2004"(5) alındı. Ankette katılımcı adı istenmemiş olup, sadece cinsiyet, yaş ve eğitim durumu (Öğrenci/Mezun) bilgileri istendi. Hazırlanan anket formu örneklem dışında kalan 20 akademisyen tarafından, soruların kapsamı, anlaşılırlığı ve diğer özellikleri açısından ön teste tabii tutuldu ve tespit edilen düzeltmeler yapıldı.

Atatürk Üniversitesi Diş Hekimliği Fakültesi Etik KuruIu'nun (15.09.2015 tarih 46 sayılı) onayı alındı. 20162017 yılı akademik eğitim-öğretim döneminin sonunda, Atatürk Üniversitesi Diş Hekimliği Fakültesi son sınıfta okuyan öğrenciler ve Erzurum ilinde çalışmakta olan, mezun diş hekimlerine, gözlem altında anket yöntemi ile çalışmanın amacı ve yöntemi açıklandıktan sonra çalışmaya katılmayı kabul eden bireylere anket çalışması uygulandı.

Anket formlarınından elde edilen veriler SPSS veri programına (Statistical Package for Social ScienceSPSS Inc. Chicago, IL, ABD) aktarılarak tanımlayıcı yöntemlerle istatistiksel analizleri gerçekleştirildi. ÇaIışmadaki değişkenler nitel değişkenler olduğu için ki kare testi yapıldı ve $p$ değeri 0,05'ten küçük olan değerler anlamlı olarak kabul edildi.

\section{Bulgular}

Çalışmaya dahil edilen 5. sınıf öğrencilere $(n=91)$ ve mezun diş hekimlerine $(n=51)$ ait grupların yaş ve cinsiyetlerine ait veriler Tablo 1'de gösterilmiştir.

Tablo 1.Çalışma grupları ve değişkenleri

\begin{tabular}{ccccc}
\hline \multirow{2}{*}{ Yaş } & & $\begin{array}{c}\text { Öğrenci } \\
\text { Ort./n. }\end{array}$ & $\begin{array}{c}\text { Mezun } \\
\text { Ort./n. }\end{array}$ & $\begin{array}{c}\text { Toplam } \\
\text { Ort./n. }\end{array}$ \\
\hline \multirow{2}{*}{ Cinsiyet } & Kadın & 57 & 27,7 & 24,6 \\
\cline { 3 - 5 } & Erkek & 29 & 28 & 85 \\
\cline { 3 - 5 } & Belirtilmemiş & 5 & - & 52 \\
\hline \multirow{2}{*}{ Toplam } & & 91 & 51 & 142 \\
\hline
\end{tabular}


Çalışmaya katılan bireylere 13 adet bilgi düzeyi değerlendirme sorusu sorulmuştur. Bu sorular, sorulara ait doğru cevaplar ve bireylerin verdikleri cevaplar Tablo 2'de gösterilmiştir. Bu sorular arasında en çok doğru cevap verilen sorular; \%92,3 ile "Hastanın yüzündeki asimetri (uyumsuzluk) değerlendirilmelidir"; \% 87,4 ile "Hastanın yüzünde uyuşukluk varlığı sorgulanmalıdır." ; \%87,3 ile "Hastanın okluzyonun- daki değişim sorulmalıdır."; \%85,9 ile "Hasta değerlendirilirken hastanın karşısından bakmak yeterlidir." ve yine \%85,9 ile "Eklem bölgesine gelen travmalar sonrası acil şikayet olmasa bile uzun dönem takip yapılmalıdır." soruları olarak görülmüştür. Doğru cevap oranının en düşük olduğu sorular ise; \%20,4 ile "Le Fort kırığı şüphesinde maksilladaki hareketlilik değerlendirilmelidir. Ancak muayenede Le Fort kırı̆ı̆ının tipi

Tablo 2. Bilgi Düzeyi Değerlendirme Soruları, Sorulara Ait Doğru Cevaplar ve Bireylerin Verdikleri Cevaplar

\begin{tabular}{|c|c|c|c|c|c|c|c|c|c|c|}
\hline \multirow[b]{2}{*}{$\begin{array}{l}\text { Doğru } \\
\text { cevap }\end{array}$} & \multicolumn{3}{|c|}{ Toplam } & \multicolumn{3}{|c|}{ Öğrenciler-1 } & \multicolumn{3}{|c|}{ Mezunlar-2 } & \multirow[b]{2}{*}{$\mathrm{P}$} \\
\hline & EVET & HAYIR & $\begin{array}{l}\text { BILGIM } \\
\text { YOK }\end{array}$ & EVET & HAYIR & $\begin{array}{l}\text { BILGIM } \\
\text { YOK }\end{array}$ & EVET & HAYIR & $\begin{array}{l}\text { BILGIM } \\
\text { YOK }\end{array}$ & \\
\hline \multicolumn{11}{|c|}{ Hastanın havayolu değerlendirilmelidir } \\
\hline EVET & 83,8 & 9,2 & 7,0 & 79,1 & 12,1 & 8,8 & 94,1 & 2,0 & 3,9 & 0,051 \\
\hline \multicolumn{11}{|c|}{ Hastanın görme gücü sorulmalıdır. } \\
\hline EVET & 72,5 & 11,3 & 16,2 & 68,1 & 14,3 & 17,6 & 80,4 & 5,9 & 13,7 & 0,22 \\
\hline \multicolumn{11}{|c|}{ Hastanın yüzünde uyuşukluk varlığı sorgulanmalıdır. } \\
\hline EVET & 87,4 & 5,6 & 7,0 & 84,6 & 8,8 & 6,6 & 92,2 & 0,0 & 7,8 & 0,092 \\
\hline \multicolumn{11}{|c|}{ Hastanın en son ne zaman yemek yediği sorulmalıdır. } \\
\hline EVET & 49,3 & 29,6 & 21,1 & 38,5 & 45,1 & 16,5 & 56,9 & 33,3 & 9,8 & 0,101 \\
\hline \multicolumn{11}{|c|}{ Hastanın öncesinde diş ağrısı olup olmadığı sorulmalıdır. } \\
\hline HAYIR & 45,1 & 40,8 & 14,1 & 42,9 & 35,2 & 22,0 & 58,8 & 21,6 & 19,6 & 0,150 \\
\hline \multicolumn{11}{|c|}{ Hastanın okluzyonundaki değiş̧im sorulmalıdır. } \\
\hline EVET & 87,3 & 7,8 & 4,9 & 83,5 & 11,0 & 5,5 & 94,1 & 2,0 & 3,9 & 0,134 \\
\hline \multicolumn{11}{|c|}{ Hastanın muayenesi öncesi radyografik değerlendirme yapılmalıdır. } \\
\hline HAYIR & 66,2 & 26,8 & 7,0 & 59,3 & 33,0 & 7,7 & 78,4 & 15,7 & 5,9 & 0,061 \\
\hline \multicolumn{11}{|c|}{ Hastanın yüzündeki asimetri (uyumsuzluk) değerlendirilmelidir. } \\
\hline EVET & 92,3 & 2,1 & 5,6 & 90,1 & 3,3 & 6,6 & 96,1 & 0,0 & 3,9 & 0,329 \\
\hline \multicolumn{11}{|c|}{ Hasta değerlendirilirken hastanın karşısından bakmak yeterlidir. } \\
\hline HAYIR & 4,2 & 85,9 & 9,9 & 5,5 & 84,6 & 9,9 & 2,0 & 88,2 & 9,8 & 0,602 \\
\hline \multicolumn{11}{|c|}{ Yüzdeki yaralanma bölgesinde olan ve olmayan tüm kemiklerin el ile muayenesi (palpasyon) yapılmalıdır. } \\
\hline EVET & 54,2 & 28,9 & 16,9 & 45,1 & 35,2 & 19,8 & 70,6 & 17,6 & 11,8 & $0,013^{*}$ \\
\hline \multicolumn{11}{|c|}{ Yabancı cisimler ve kırık diş parçaları çıkarılmalıdır. } \\
\hline EVET & 69,0 & 11,3 & 19,7 & 63,7 & 13,2 & 23,1 & 78,4 & 7,8 & 13,7 & 0,192 \\
\hline
\end{tabular}

Le'fort kırığı şüphesinde maksilladaki hareketlilik değerlendirilmelidir. Ancak muayenede Le'fort kırığının tipi ile ilgili bilgi edinilemez.

\begin{tabular}{|c|c|c|c|c|c|c|c|c|c|c|}
\hline HAYIR & 54,9 & 20,4 & 24,7 & 56,0 & 14,3 & 29,7 & 52,9 & 29,4 & 17,6 & 0,057 \\
\hline
\end{tabular}

Eklem bölgesine gelen travmalar sonrası acil şikayet olmasa bile uzun dönem takip yapılmalıdır.

\begin{tabular}{|c|c|c|c|c|c|c|c|c|c|}
\hline EVET & 85,9 & 3,5 & 10,6 & 84,6 & 3,3 & 12,1 & 88,2 & 3,9 & 0,725 \\
\hline
\end{tabular}

${ }^{*} \mathrm{p}<0,05$ anlamlılık düzeyinde istatisksel olarak anlamlı kabul edilmiştir 
ile ilgili bilgi edinilemez."; \% 26,8 ile "Hastanın muayenesi öncesi radyografik değerlendirme yapılmalıdır." ve \%49,3 ile "Hastanın en son ne zaman yemek yediği sorulmalıdır." soruları olarak görülmüştür.

Ayrıca; cevaplandırılması istenen "Hastanın öncesinde diş ağrısı olup olmadığı sorulmalıdır." sorusu için, bireylerin \%40,8'i doğru cevap olan "HAYIR" şıkkını işaretlemişlerdir. Çalışma grupları açısından; 5. Sınıf öğrencilerinin \%35,2'si ve mezunların \%21,6'sı bu soruyu doğru cevaplamışlardır ve gruplar arasında istatistiksel olarak anlamlı fark olmadığı görülmüştür ( $p>0.05)$. Cevaplandırılması istenen "Hastanın muayenesi öncesi radyografik değerlendirme yapılmalıdır." sorusu için, bireylerin sadece \%26,8'i doğru cevap olan "HAYIR" şıkkını işaretlemişlerdir. Çalışma grupları açısından; 5. Sınıf öğrencilerinin \%33'ü ve mezunların \%15,7'si bu soruyu doğru cevaplamışlardır ve gruplar arasında istatistiksel olarak anlamlı fark olmadığı görülmüştür ( $p>0.05$ ). Çalışmaya katılan bireylere "Yüzdeki yaralanma bölgesinde olan ve olmayan tüm kemiklerin el ile muayenesi (palpasyon) yapılmalıdır. " sorusu sorulmuş ve 5. Sınıf öğrencilerinin $\% 45,1$ 'i, mezunların \%70,6'sı olmak üzere toplamda \%54,2 oranda "EVET" cevabı alınmıştır. Gruplar arasında istatistiksel olarak anlamlı farklılık olduğu görülmüştür $(p=0,01)$.

Çalışmaya katılan bireylere 7 adet subjektif değerlendirme sorusu sorulmuştur. Bu sorulara bireylerin verdikleri cevaplar Tablo 3'de gösterilmiştir. Cevaplandırılması istenen subjektif değerlendirme sorularından "Maksillofasiyal travma ile karşılaştınız mı?" sorusuna 5. sınıf öğrencilerinin \% 23,1'i "EVET" cevabını verirken, mezunların \%54,9'u "EVET" cevabını vermişlerdir. Bu sonuçlara göre, mezun katılımcıların öğrencilere kıyasla istatistiksel olarak anlamlı derecede daha çok $(p=0,000)$ maksillofasiyal travma ile karşı-

Tablo3. Subjektif Değerlendirme Soruları ve Bireylerin Verdikleri Cevaplar

\begin{tabular}{|c|c|c|c|c|c|c|}
\hline \multicolumn{2}{|c|}{ Toplam } & \multicolumn{2}{|c|}{ Öğrenciler-1 } & \multicolumn{2}{|c|}{ Mezunlar-2 } & \multirow[b]{2}{*}{$\mathrm{P}$} \\
\hline EVET & HAYIR & EVET & HAYIR & EVET & HAYIR & \\
\hline \multicolumn{7}{|c|}{ Maksillofasiyal travma ile karşılaştınız mı? } \\
\hline 29,6 & 70,4 & 17,6 & 82,4 & 47,1 & 51,0 & $0,000^{*}$ \\
\hline \multicolumn{7}{|c|}{$\begin{array}{l}\text { Klinik muayenede kondil kırığını teşhis edebileceğinizi düşünüyor } \\
\text { musunuz? }\end{array}$} \\
\hline 42,3 & 57,7 & 38,5 & 61,5 & 49,0 & 51,0 & 0,222 \\
\hline \multicolumn{7}{|c|}{$\begin{array}{l}\text { Intermaksiller fiksasyon konusunda yeterli bilgiye sahip olduğunuzu } \\
\text { düşünüyor musunuz? }\end{array}$} \\
\hline 4,2 & 95,8 & 2,2 & 97,8 & 7,8 & 92,2 & 0,109 \\
\hline \multicolumn{7}{|c|}{$\begin{array}{l}\text { Barton bandajı hakkında yeterli bilgiye sahip olduğunuzu düşünüyor } \\
\text { musunuz? }\end{array}$} \\
\hline 1,5 & 98,5 & 0,0 & 100 & 3,9 & 96,1 & 0,057 \\
\hline \multicolumn{7}{|c|}{$\begin{array}{l}\text { Dental travma ile karşılaştığınızda yeterli müdahaleyi yapabileceğinizi } \\
\text { düşünüyor musunuz? }\end{array}$} \\
\hline 23,9 & 76,1 & 14,3 & 85,7 & 41,2 & 58,8 & $0,000^{*}$ \\
\hline \multicolumn{7}{|c|}{$\begin{array}{c}\text { Dental ve maksillofasiyal travma sonrası başvuran hastalar için doğru } \\
\text { teşhisi koyabileceğinizi düşünüyor musunuz? }\end{array}$} \\
\hline 14,1 & 85,9 & 7,7 & 92,3 & 25,5 & 74,5 & $0,011^{*}$ \\
\hline \multicolumn{7}{|c|}{$\begin{array}{l}\text { Maksillofasiyal travma ile karşılaştığınızda yeterli müdahaleyi } \\
\text { yapabileceğinizi düşünüyor musunuz? }\end{array}$} \\
\hline 1,5 & 98,5 & 0 & 100 & 3,9 & 96,1 & 0,057 \\
\hline
\end{tabular}


laştıkları görülmüştür. Katılımcıların cevaplaması istenen subjektif soruların tümünde toplamda "HAYIR" cevaplarının büyük çoğunluk teşkil ettiği görülmüştür.

\section{Tartışma}

Maksillofasiyal travma, çene ve yüz bölgesini ilgilendiren, bir bölgedeki küçük bir laserasyondan çoklu ve parçalı kemik kırıklarına, hatta büyük doku kayıplarına kadar çok geniş bir yelpazede görülebilirler.(6) Maksillofasiyal travmaların üçte ikisi motorlu araç kazaları ve kavga sonucu oluşmaktadır. Maksillofasiyal travmaların ciddi bir kısmına acil tıp birimleri tarafından müdahale yapılması gerekmektedir. \%50-60'ı kadarında maksillofasiyal bölge dışında başka bir organ sisteminde de hasar vardır. Bu travmalara \%51 kafa, $\% 12$ göğüs, \%5 karın ve \%33 oranında da iskelet sisteminde görülen yaralanmalar eşlik etmektedir.(7)

Diş hekimliğinde temel maksillofasiyal travma eğitimi ile amaçlanan hekimlerin maksillofasiyal travma konusunda ön tanıyı ve doğru yönlendirmeyi yapabilecek bilgi ve tecrübe seviyesine ulaşmalarıdır.(8) Çaıışmamızın sonuçlarına göre, subjektif değerlendirme sorularına verilen cevaplar incelendiğinde, hekimlerin hem teşhis hem de tedavi için yeterli olmadıklarını belirttikleri görülmüştür. Bu sonuçlar, diş hekimliği fakültelerinde verilen teorik eğitimin niteliği yeterli olsa dahi hekimlerin maksillofasiyal travma ile karşılaşma oranının $(\% 29,6)$ düşük olması sebebiyle teşhis koyma konusundaki tereddütlerinin yüksek düzeyde olmasını düşündürmektedir. Ayrıca, mezun diş hekimlerinin bilgi düzeylerinin her soruda daha yüksek olduğu görülmüştür. Mezun diş hekimlerin maksillofasiyal travma ile karşılaşma oranının $(\% 47,1)$, stajyer diş hekimlerine kıyasla $(\% 17,6)$ ve istatistiksel olarak anlamlı derecede yüksek $(p<0,05)$ olmasının bu duruma sebep olduğu düşünülmüştür.

Doğru cevap oranının en düşük olduğu soru \%20,4 ile "Le Fort kırığı șüphesinde maksilladaki hareketlilik değerlendirilmelidir. Ancak muayenede Le Fort kırığının tipi ile ilgili bilgi edinilemez." sorusu olmuştur. Bu soruya verilen cevabın düşük oranda kalmasının nedeni olarak yine bu durumla karşılaşma oranının düşük olması olduğunu düşünmekteyiz. Doğru cevap oranının en düşük olduğu diğer bir soru; \% 26,8 ile "Hastanın muayenesi öncesi radyografik değerlendir- me yapılmalıdır." sorusu olmuştur. Tintinalli Acil Tıp: Kapsamlı Bir Çalışma Kılavuzu'nda(5) belirtildiği üzere, önce muayene sonra radyografik değerlendirme yapılmalıdır. Maksillofasiyal aciller için hızı ve doğru bir klinik muayene temel teşkil etmektedir. Doğru cevap oranının en düşük olduğu başka bir soru ise; \%49,3 ile "Hastanın en son ne zaman yemek yediği sorulmalıdır." sorusu olarak görülmüştür. Yine aynı kaynakta belirtildiği üzere bu bilgi, genel anestezi ve sedasyon ihtiyacı anında hızlı karar alabilmek için, ilk muayene aşamasında öğrenilmesi ve kaydedilmesi gereken bir veridir.

Literatür tarandığında, dental ve medikal aciller konusunda çalışılmış çeşitli çalışmalar olmakla birlikte, maksillofasiyal travmalar ve aciller hakkında yapılmış benzer bir çalışmaya rastlanılmamıştır. Diş hekimliği fakültesinde öğrenim görmekte olan son sınıf öğrencilerinin medikal aciller konusunda bilgi düzeylerini değerlendiren bir anket çalışmasında, katılımcıların bilgi düzeylerinin yüzeysel olduğu gösterilmiş olup, bilgi düzeylerinin artırıması için uygulamalı pratik eğitim gerekliliğini önermişlerdir.(4) Diş hekimlerinin medikal aciller konusunda bilgi düzeylerini değerlendiren bir anket çalışmasında, katılımcıların medikal aciller ve temel yaşam desteği konularında bilgi düzeylerinin yetersiz olduğu belirtilmiştir.(3) Diş hekimlerinin dental travmalar konusundaki bilgi düzeyini değerlendiren bir anket çalışmasında, katılımcıların bilgi düzeyi "orta seviye" olarak belirlenmiştir.(9) Benzer bir çalışmada, diş hekimliği öğrencilerinin dental travmalar konusundaki bilgi düzeyleri değerlendirilmiş olup, katılımcıların bilgi düzeylerinin yetersiz olduğu belirtilmiştir.(10) Tıp fakültesinde öğrenim görmekte olan öğrencilerin dental travmalar konusunda bilgi düzeylerini değerlendiren bir anket çalışmasında, katılımcıların yetersiz bilgi düzeyine sahip olduğu görülmüştür.(11) Tüm bu çalışmaların ortak çıkarımı olarak, vakaya göre değişkenlik gösteren dental ve medikal aciller gibi alanlarda mutlaka klinik gözlem ve pratik uygulamalar ile desteklenmiş teorik eğitim planlanmasının önemi görülmüştür.

\section{Sonuç}

Çalışma sonuçlarımız değerlendirildiğinde; hem stajyer hem de mezun diş hekimlerinin maksillofasiyal travmalar konusundaki bilgi düzeylerinin kabul edi- 
lebilir olmasına rağmen katılımcıların bu konudaki tedirginliklerinin oldukça yüksek olduğu görülmüştür. Lisans eğitimi ve mesleki uygulama süresince edinilen teorik bilgilerin, klinik olarak vaka ile karşılaşma oranının artırılması ile güçlendirilmesi gerektiği ve bu konuda gereken eğitim stratejisinin oluşturulması gerekliliği sonucuna varılmıştır.

\section{Kaynaklar}

1. Ferraro JW, Hakola S. Fundamentals of maxillofacial surgery. Springer Science \& Business Media; 2012.

2. Miloro M, Ghali GE, Larsen P, Waite P. Peterson's principles of oral and maxillofacial surgery. Vol. 1. PMPH-USA; 2004.

3. Stafuzza TC, Carrara CCF, Oliveira FV, Santos CF, Oliveira TM. Evaluation of the dentists knowledge on medical urgency and emergency. 2014;28(1):1-5.

4. Jodalli PS, Ankola A V. Evaluation of knowledge, experience and perceptions about medical emergencies amongst dental graduates ( Interns ) of Belgaum City , India. 2012;4(1):14-8.

5. Hung OL, Nelson L. Tintinalli's emergency medicine: a comprehensive study guide. McGraw-Hill, New York; 2004.

6. Andersson L, Kahnberg K-E, Pogrel MA. Oral and maxillofacial surgery. John Wiley \& Sons; 2012.

7. Demetriades D, Asensio J a. Trauma Management. Landes Bioscience, USA; 2000.

8. Diş Hekimliği Eğitim Programları Değerlendirme Ve Akreditasyon Derneği. Mezuniyet Öncesi Ulusal Diş Hekimliği Çekirdek Eğitim Programı. 2014;

9. Akhlaghi N, Nourbakhsh N, Khademi A, Karimi L. General Dental Practitioners' Knowledge about the Emergency Management of Dental Trauma. 2014;9(4):251-6.

10. Fujita Y, Shiono Y, Maki K. Knowledge of emergency management of avulsed tooth among Japanese dental students. BMC Oral Health [Internet]. 2014;14(1):1-6. Available from: BMC Oral Health

11. Eden E, Kilinç G, Ellidokuz H. İzmir İlindeki İki Tıp Fakültesine Devam Eden Son Sınıf Öğrencilerinin Dental Travmaya Yaklaşımları. Dokuz Eylül Üniversitesi Tıp Fakültesi Derg. 2011;25(1):31-7. 